\title{
An exploration of engagement in community based creative activities as an occupation for older adults
}

\author{
Luned Edwards \\ School of Social and Life Sciences, Glyndwr University, Wrexham, UK \\ Bethan Owen-Booth \\ Glyndwr University, Wrexham, UK
}

\begin{abstract}
Purpose - The purpose of this study was to explore the experiences of older adults (aged 60 and over) participating in community-based creative arts. With an ever increasing ageing population, understanding the benefits of leisure occupations such as community creative arts will be vital for Occupational Therapists in facilitating participation and active engagement.

Design/methodology/approach - An empirical qualitative research design with an interpretive phenomenological approach was undertaken. A purposive sampling method enlisted four older adult volunteers whose experiences of creative arts were explored through semi-structured interviews. Interview data were analysed thematically.

Findings - Participants identified many benefits of engaging in community creative arts. Four main themes were identified, namely, "personal benefits", "choice" in their occupation, "encouragement" to and from others, with the environment facilitating "socialising". These resulted in improved occupational performance and positive well-being outcomes.

Originality/value - The study complements national policy and extends evidence-based practice on the potential well-being benefits on older adults. In support of the preventative agenda, occupational therapists may apply these findings to increase social prescribing within practice.
\end{abstract}

Keywords Community, Occupational therapy, Older adult, Social prescribing, Creative arts

Paper type Research paper

\section{Introduction}

There are 800,000 people aged 50 and over in Wales, where this study is based, and are projected to rise in the next 20 years by one million (Office of National Statistics, 2018). Living longer poses a unique set of challenges including an increase in chronic conditions and additional financial costs to the National Health Service and Social Care (Royal College of Occupational Therapy (RCOT), 2017; Stickley et al., 2016). Welsh public policy endorses preventative measures to promote positive active ageing for optimum health and well-being amongst adults over 50 (Welsh Government, 2014; Ageing well in Wales, 2014). Occupational therapy is at the forefront of the preventative agenda and health promotion by supporting and enabling participation in meaningful occupations (Royal College of Occupational Therapy, 2017; Andonian and MacRae, 2011).

\section{Literature review}

Creative Arts encompasses a wide spectrum of mediums including painting, drawing, and music. Expanding evidence

The current issue and full text archive of this journal is available on Emerald Insight at: https://www.emerald.com/insight/2398-8819.htm

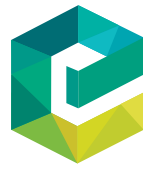

Irish Journal of Occupational Therapy

49/1 (2021) 51-57

Emerald Publishing Limited [ISSN 2398-8819]

[DOI 10.1108/IJOT-05-2020-0009] supports the positive contribution and impact of creative arts as a leisure-based occupation on older adults (Fraser et al., 2015; Gallistl, 2018; Poulos et al., 2019). Occupational engagement in creative arts can assist in addressing the challenges of an ageing population by maintaining good health, aid recovery from illness and support people to live fulfilled lives (Roe et al., 2016). Activities that encompass the needs of older adults through engaging in purposeful, meaningful occupations are key underpinning philosophy of occupational therapy (Royal College of Occupational Therapy, 2017). This is further supported by Wilcock's (2005) ideology that emphasises the importance of occupation in promoting health and well-being.

The National Institute of Clinical Excellence (2015) recommends group creative arts as an intervention to maintain and improve mental well-being and independence for people aged 65 and over. Community-based organisations are well

(C) Luned Edwards and Bethan Owen-Booth. Published in Irish fournal of Occupational Therapy. Published by Emerald Publishing Limited. This article is published under the Creative Commons Attribution (CC BY 4.0) licence. Anyone may reproduce, distribute, translate and create derivative works of this article (for both commercial and non-commercial purposes), subject to full attribution to the original publication and authors. The full terms of this licence maybe seen at http://creativecommons.org/licences/ by/4.0/legalcode

Received 4 May 2020

Revised 9 November 2020

7 February 2021

Accepted 23 February 2021 
positioned to provide accessible, informal and user-led activities, suited to local interests and needs (Clift, 2012). The environment in which creative art takes place and the subsequent benefits of social interaction is acknowledged (Stuckey and Nobel, 2010; Phinney et al., 2014). Holt-Lunstad et al. (2015) carried out a meta-analytical review and found that loneliness and isolation had a detrimental effect, influencing mortality by up to nine years. Social networks and friendships can reduce the risk of mortality or developing certain diseases and aid in supporting individuals to recover from illness (Leigh-Hunt et al., 2017; Papageorgiou et al., 2016). O'Shea and Leime (2012) suggest that interacting with peers provides an opportunity for older adults to self-manage their occupations and creates a sense of belonging and purpose. This supports Wilcock's (1998) theory of the "doing, being and becoming" occupational therapy framework of participating in meaningful occupations (Hammell, 2014). Cantu and Fleurit (2017) study involving 138 participants strongly advocated engaging in community creative art to enhance mood, emotions and their overall mental well-being. Stickley et al. (2016) and Poulos et al. (2019) identified wider outcomes on individuals; sense of self, expression and building social support. Although a growing wealth of evidence supports the positive contribution and impact of creative art, there is no consensus on what aspects are deemed important to older adults (Arts Council for Wales, 2018). Furthermore, there is limited knowledge about how their participation in community create arts impact their lives (Cantu and Fleuriet, 2017; Clift, 2012). McAvinchey (2013) states participation in creative arts amongst older adults is one of the most substantial, emerging and under researched area. There is palpable absence of contemporary empirical evidence about the experience, effects and benefits of creative arts as a leisure pursuit for older people in community settings (Roe et al., 2016; Cantu and Fleuriet, 2017). Studies by Roe et al. (2016) and Poulos et al. (2019) focus on evaluating short term professionally taught creative arts classes as opposed to sustained participation in community creative arts. Previous research predominantly do not account for the 50-65 age range with gender imbalance evident amongst volunteers acknowledged (Roe et al., 2016). This coincides with Cantu and Fleuriet's (2017) theory that females are generally more active in community social activities. Studies typically adopted qualitative research with small samples included and therefore do not represent the total experience of all older adults participating in community creative art groups.

It is worthy that occupational therapy services understand the potential productive, pleasurable and restorative benefits of creative arts to socially prescribe older adults to community activities (Cantu and Fleuriet, 2017). Social prescribing connects individuals to local non-medical and social welfare support opportunities in their local community for increased well-being (Thew et al., 2017). In accordance with their intervention plan, occupational therapists could encourage individuals to self-refer to creative art groups or refer to social prescribing coordinators based in the Welsh voluntary sector. A systematic review by Small field and Molitor (2018) recommend embedding social prescribing routinely in occupational therapy services. Although the American study focusses on leisure education programmes, the benefits of connecting with peers could be deemed as transferable to other community leisure groups.

This study aims to contribute towards the limited contemporary research available on older people's experience and engagement in community creative arts. The exploration supports occupational science by providing knowledge about human occupation, thus contributing towards early intervention and national policy. Literature recognises that the person, occupation and the environment interplay to enable occupational performance and engagement in creative arts (Law et al., 1996; Perruza and Kinsella, 2010; Reynolds, 2009). The Person-Environment-Occupation (PEO) model (Law et al., 1996) provides a framework to explore and understand the complex connections amongst factors that result in occupational performance. (Vrkljan, 2010). This model was adopted to identify how the person, occupation and environment interact to aid performance and engagement in creative arts. The PEO model was selected, as it provided clear and adequate detail of what we should be considering when analysing the person, environment and occupation.

\section{Method}

An empirical qualitative approach was deemed the most suitable research design to acquire analytical insights into the engagement of community-based creative art for older adults (Clift, 2012; Braun and Clark, 2006). Utilising open-ended questioning, qualitative research depicts words from participants own narrative including their attitudes, behaviours and values (Denscombe, 2017). This allows the identification of rich, meaningful, unstructured data that could not be captured utilising quantitative methods (Kumar, 2014). Implementing the interpretivist phenomenological approach aided understanding the perspective of older people engaging in creative arts at an Age Well centre, encompassing cultural and social aspects (Denscombe, 2014). Evidence was collated to answer questions with the researcher recognised as part of the reality (Aveyard, 2014). This ethos supports the core principles of occupational therapy as the profession is rooted in human experience, meaning and client centeredness (Royal College of Occupational Therapy, 2017).

\section{Recruitment}

The research focused on an Age Well Centre that offers a plethora of services and leisure activities for adults aged 50 and over. Located in a rural town, the centre is a registered charity governed by an independent board of Trustees, steering group with a part time coordinator. Members pay a modest annual fee to attend weekly timetabled creative arts groups. Due to its high membership, this research focussed on the non-structured art group for increased likelihood of recruiting participants. Purposive sampling method enlisted four volunteers with the inclusion criteria of; over fifty, no cognitive deficits and had attended the art group for at least three months (Aveyard, 2014). This increased the probability of valuable data (Kumar, 2014). The centre's coordinator willingly acted as a gatekeeper and verified all members conformed to the inclusion criteria. Access to the group was permitted by the Age Well centre board, allowing the researcher to present the research and disseminate a detailed information sheet. Participants 
completed a pre-interview questionnaire to provide background information.

\section{Participants}

Participants were two women (P1, P4) and two men (P2, P3) between 60 and 80 years, mean age of 71 ; Table 1 presents participant characteristics. Mean membership length was 3.5 years and all self-referred to the art group. All independently mobile and lived within three miles of the centre. One participant walked or received a lift from other members to the centre with the remaining three using own vehicle.

\section{Ethics}

Ethical approval was granted by the researcher's University Research Ethics Standing Committee. Permission in writing was provided by the Age Well board. Upholding participant beneficence, interview particulars were arranged through the gatekeeper and held in a secure room for confidentiality (Aveyard, 2014). Participants signed a bilingual consent form, enabling informed consent and were made aware they could withdraw at any time (Denscombe, 2017). The anonymity and confidentiality of the participants were maintained by adopting pseudonyms throughout the research process.

\section{Data collection}

Semi-structured interview questions provided a logical framework with flexibility to probe for clarity of the phenomenon, see sample questions (Denscombe, 2017):

Q1. Is art a new interest or have you previously participated in art activities?

Q2. What are the main reasons you attend the art group at the Age Well centre? How does participating in the art class make you feel?

Q3. What would you say are the benefits of attending the group?

Q4. What factors make it difficult for you to take part in the art group?

Q5. What would you change about the group?

Q6. What would you like to achieve in the art group in the future?

Questions centred on the PEO model (Law et al., 1996) to offer flexibility regarding the extent to which occupational performance was addressed. The questions were piloted with two independent older adults (78 and 79 years) to obtain feedback, supporting trustworthiness and rigor (Elo et al., 2014). Following consent, each interview was audio recorded, average duration of ten minutes. By using a reflective journal, reflexivity was conducted throughout the qualitative process to improve the rigor of the data collection (Kumar, 2014).

\section{Data analysis}

Deductive thematic analysis was deemed suitable for this research to provide common themes that connected to the PEO model (Braun and Clarke, 2006; Law, 1996). It is a framework for identifying, analysing, organising, describing, and reporting themes originated within a data set (Aveyard, 2014). According to Braun and Clarke (2006) the framework is particularly effective for researching areas of which there are limited studies. Interview data was transcribed accurately and anonymously; one translated from Welsh to English. To increase rigor, member checking took place to confirm transcript (Kumar, 2014). Primary raw data from notes and audio recordings was accurately transcribed, catalogued and indexed. Unique serial numbers were allocated as references to aid navigation and record significant data (Denscombe, 2017). Salient points with initial codes were formulated, categorising segments of similar content and reviewed for transparency, aiding trustworthiness and dependability (Elo et al., 2014). Connections identified between colour coded words and phrases resulted in the formation of four themes with sub themes (Aveyard, 2014). The themes represented significant threads emerging from the data relating to the aim and objectives of the study. The researcher deliberated on reflexivity by remaining subjective and mindful of any bias, assumptions and preconceptions that could prevent the exploration of identified key themes and interpretation (Elo et al., 2014).

\section{Findings and discussion}

The data analysis yielded four themes identified in Figure 1. Under the environment component, socialising theme was identified with three sub-categories. Personal benefits were identified under the person component with three sub themes. The occupation component revealed two sub themes; encouragement and choice, each with three sub themes.

\section{Role and impact of creative arts on the person}

"Personal benefits" were multifaceted as accepted within occupational science and highlighted the role and impact of creative arts on the person (Fraser et al., 2015). They felt a sense of achievement and worth from their occupation, specifically when a piece of art was completed, supporting previous research findings by Hammell (2014) and Riley et al. (2013):

It makes me feel I've done somethings worthwhile (P3).

When I get home, I feel as if I've achieved something (P1)

Table 1 Participant characteristics

\begin{tabular}{llllll}
\hline Name & Gender & Age & Marital status & Employment history & Living situation \\
\hline P1 & Female & 60 & Divorced & Retired & Living alone \\
P2 & Male & 62 & Married & Carer for spouse & Living with spouse \\
P3 & Male & 80 & Married & Retired & Living with spouse \\
P4 & Female & 80 & Widow & Retired & Living alone \\
\hline
\end{tabular}


Figure 1 Thematic map of the research themes and sub themesDerived from the PEO Model

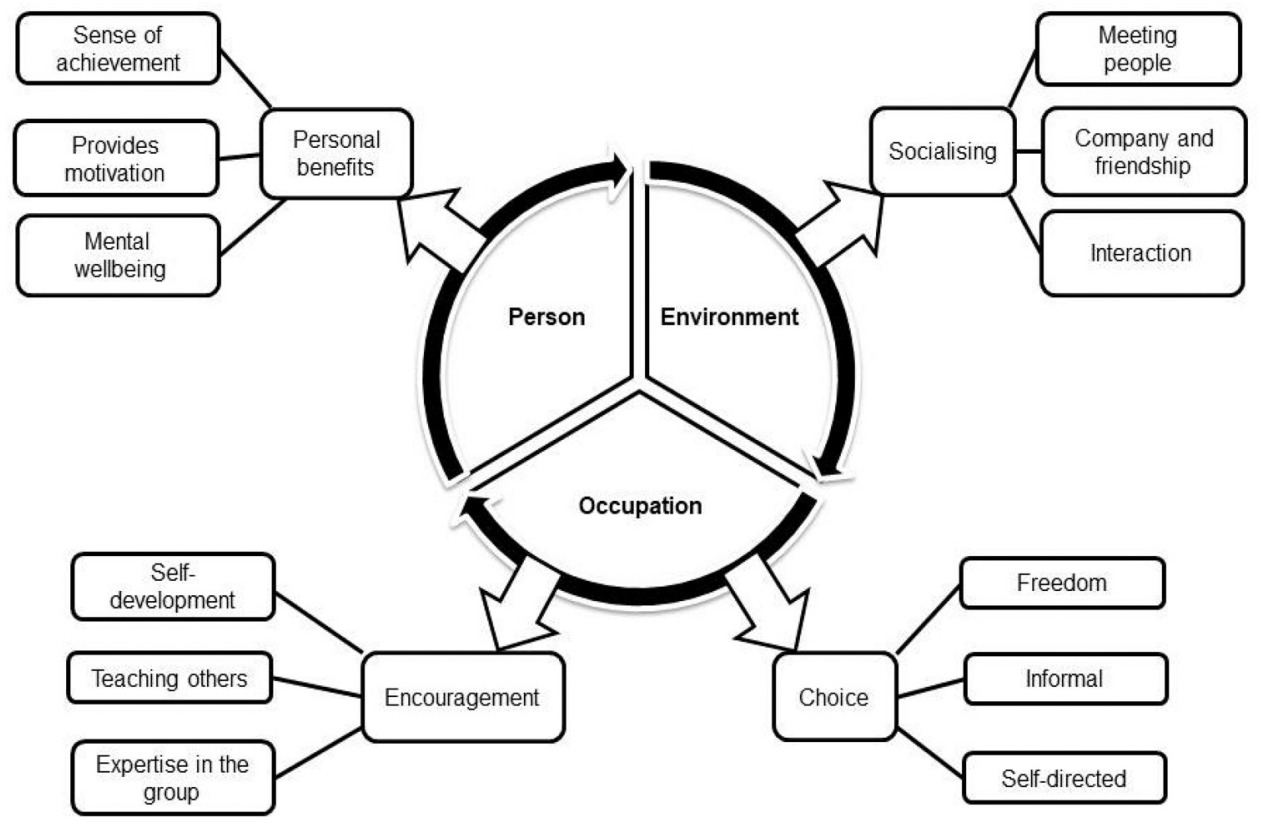

Source: Law et al. (1996)

I feel a sense of achievement when I manage to complete a reasonable painting (P2)

The value of the art group as an occupation was specified. One participant stated that the group provided self-motivation and focus to get out of the house. It gave the opportunity for participating in an activity, providing structure and discipline to their lives:

Pass the time; I have to have something to do (P3).

Self-motivation, get myself kicked up the bum to get out of the door! (P1).

Positive mental well-being was articulated by all participants, supporting existing research by Cantu and Fleuriet (2017) who attribute creative arts benefits on physical health and psychological well-being. One participant acknowledged walking to the centre for the art group aided physical health. Overwhelming positive responses conveyed how the group made them feel during and following each session:

Makes me feel good, usually go home with a smile on my face (P4).

Fantastic. It's a bit of both (physical and mental), makes me come here so I'm moving about and it helps me deal with the past and gives me focus so I'm happier (P1).

Enjoyment and to feel relaxed were mainly identified however emphatic statements referred to dealing with challenging personal experiences. This coincides with research by Cantu and Fleuriet (2017) that engaging in CA can positively impact mood and emotions thereby reducing stress, anxiety and managing depression (Holt-Lunstad et al., 2015). One participant attributed the group to direct physical and mental health benefits by dealing with negative emotions associated with historic domestic abuse. Attending the group provided respite for one full-time carer and helped to cope with the role:

Getting away from daily life [...] basically to get out and meet people as I said before I'm a full time carer so I need a break (P2).
The participants did not disclose physical disabilities however; the multifaceted sources of well-being inherent in community creative art have potential for offering fulfilment to people living with long term physical and mental health conditions. This supports the preventative agenda in active aging (Ageing Well in Wales, 2014).

\section{Creative arts as a meaningful occupation}

"Choice" and "encouragement" were identified as two themes. Three participants had attended formal art classes whilst one stated creative arts was part of their productivity role before retirement. Participants ceased attending classes due to their rigid structure, formality and dictation. Although a facilitator had overall responsibility for the group, not having a formal teacher was positively and strongly acknowledged. Participants preferred the freedom and choice of pursuing their desired and meaningful occupation within the group. "Choice" is a novel theme, implying that consulting participants on the type, structure and content of community creative arts is imperative. This is not indicative in previous research and contradicts Cantu and Fleurit (2017) study where participants valued skills and knowledge acquired by formal teaching. The group empowered and encouraged individuals to be self-directed, highlighting what they wanted to achieve at the centre, at their own pace. This resulted in an informal and relaxed atmosphere:

This group is exactly what I wanted because you're not being taught anything, you're just being helped by people that know and everybody does their own thing (P2).

You do what you want to paint and how you want to paint it. It's a great group because nobody er we don't have a teacher we all do our own thing but we all help one another (P4).

Participants derived numerous personal satisfactions from the group. The learning ensued was greatly valued, coinciding with 
research by Gallistl (2018) of acquiring and developing skills. Participants were in control of their learning needs, with focus on individual activity to build on existing knowledge and skills:

I'm learning to do figures at the moment, I've never done them, well, not done since I was at college anyway (P1).

I'm rubbish at watercolours but learning [....] (P4).

Participants did not distinguish self-development aims in the creative arts, differing to research by Riley et al. (2013) whose participants engaged in other creative arts occupations. Participants of this study unanimously communicated their desire for the group to continue without revisions. One participant stated that any modifications would result in a change in dynamics and a reduction in membership. This suggests that the group fulfils the occupational needs of the participants.

The opportunity to be encouraged, to learn and be advised by others was expressed supporting the potential of peer learning in occupation. Utilising the capabilities of others enriched the class, echoing studies by Gallistl (2018) and O'Shea and Leime (2012) of acquiring knowledge and developing skills along with pursuing new opportunities (Stickley et al., 2016).

One participant reflected on the possibility of sharing personal knowledge and skills of framing artwork with other members. Utilising individual expertise, strengths and skills meant there was always someone to provide assistance and support if required. This corroborates with research by Riley et al. (2013) that partaking in a mutual interest in a group setting aided in the formation of new skills highlighting the benefit of peer led learning. Peer learning enable the fulfilment of occupation whilst supporting positive health and well-being outcomes:

There's a load of talent in this group and everybody's willing to pass on what they know (P2).

A lot of people have retired and have not worked for years and have no other skills and there are some that come to the centre with no idea about how to "draw". They ask me, you know, how to do the work and er how to do the drawings and all kinds of things. We all help each other here! (P3).

One participant particularly enjoyed the process of teaching others and offering knowledge, linking to previous roles in productivity and leisure occupations. The participant added it was satisfying to witness the personal development of members who had benefited from the expertise of others and their time with the group"

The amount of people that've walked into the class and they said "Oh I can't do that" and we said "well come and try", then a while later they're doing work that they thought they could never do (P2).

\section{Role of the environment of an Age Well centre in promoting occupational performance and engagement}

The Age Well centre offers an outlet for social interaction and engagement with their chosen activity, resulting in positive benefits to overall well-being. "Socialising" was unanimously advocated by all participants as an important attribute, specifically the interactive and positive relationships established. This can reduce the risk of mortality or developing certain diseases (Leigh-Hunt et al., 2017; Royal College of Occupational Therapy, 2017; Hammell, 2014). The occupation and the social aspect were deemed equally important and linked to participant enjoyment. The centre facilitated the opportunity for members to meet different people, those who had a mutual art interest and to engage with their occupation. Participants highlighted the value of laughter and humour, friendliness of the group and camaraderie. This resulted in the formation of valued friendships:

I enjoy mixing with everybody else, having a good old natter and doing me art in between [...] [...] I enjoy the company there, I enjoy, talking you know. It's being with other people more than anything you know and not stuck at home (P1).

Basically to get out and meet people and er as I said before I'm a full time carer so I need a break (P2)

Main benefits meeting people and socializing [. . .] laughing! (P3).

I really enjoy the painting and I enjoy the company and friendship definitely [...] [...] we laugh a lot (P4).

The benefits of forming highly meaningful, supportive social connections through community have been reported in previous studies (McAvinchey, 2013; Phinney et al., 2014). Formation of positive relationships with peers was supports Wilcock's (1998) theory of "belonging". Literature recognises the vital role of occupational therapy in supporting social participation through occupations to promote healthy aging (Andonian and MacRae, 2011; Royal College of Occupational Therapy, 2017). Attending community create arts could reduce the detrimental and adverse effects of social isolation in older adults (Holt-Lunstad et al., 2015).

In consideration of the themes collectively, it may be interpreted that participants manifested characteristics of positive ageing. They expressed high satisfaction with the group through social connectedness with peers choice and control over their occupation.

\section{Implications}

Previous studies acknowledged a lack of consensus about how participation in community create arts impact the lives of older people (Cantu and Fleuriet, 2017; Clift, 2012).The findings of this small study aimed to contribute towards limited yet emerging empirical evidence available on the experiences and engagement of older adults in community creative arts (McAvinchey, 2013). This study corroborates current literature that outlines creative arts as a positive leisure-based occupation on aging well. Community creative arts are recognised in national policy by fostering learning, social connections with peers, enhanced well-being and quality of life (Fraser et al., 2015; Gallistl, 2018; Poulos et al., 2018). The findings add to evidence-based practice in understanding the preventative and restorative potentials of creative arts as an occupational therapy intervention and value as a creative leisure occupation (Poulos et al., 2018). This study offers occupational science insights to understand the meaning and benefits of older adults engaging in creative arts, adding to limited existing literature. The research aids clinical reasoning for social prescribing as part of a holistic occupational therapy intervention plan. "Choice" to pursue their desired art occupation in a non-taught manner was highlighted as a novel theme, to be considered when developing community creative arts groups. 


\section{Limitations of the study and further research}

The researcher consciously acknowledged own assumptions and preconceptions by using a reflective journal throughout the study however it is acknowledged reflexivity may affect qualitative research outcomes (Aveyard, 2014). Despite considered adequate in an interpretive phenomenological research, a small sample size of four participants were included in this study (Denscombe, 2017). Similarly to previous qualitative studies of this nature, this does not represent the experiences of all older adults who attend the art group. As the participants interviewed were of white British origin, the data collected is limited to this demographic. Volunteers for this study identified themselves as having no physical conditions and no occupational barriers which may not be indicative of this age group. A culturally diverse sample, older adults with physical conditions and research conducted in urban and rural settings could be considered in future research. Alternative community creative arts provision, either taught or self-directed, could be also considered for future research. Older females were primarily the focus of previous creative art studies, therefore further representation of older males should be a priority to support balanced gender perspectives. Accommodating these limitations in future studies could results in wider predictions. Eluded in previous studies and this research, the potential of creative art occupations to promote individuals well-being and community cohesion warrants further study (Roe et al., 2016; Riley et al., 2013).

\section{Conclusion}

Through a rich description of experiences, this empirical qualitative research provides the perspective of older adults engaging in community-based creative arts occupation in an Age Well centre. Participants identified personal benefits from occupational engagement with sense of achievement conveyed following completion of work, motivated their attendance and positively impact their mental well-being. The environment enabled participants to meet and socialise, resulting in the formation of friendship. This research contributes towards expanding evidence advocating the use of creative arts as a leisure occupation with important well-being gains to older adults, thereby supporting national policy. To support and sustain healthy aging, it is imperative that occupational therapy services utilise occupational science to understand the role and importance of creative arts to older people and their well-being benefits. There is a clear role for occupational therapists to promote community creative arts groups through social prescribing.

\section{References}

Ageing Well in Wales (2014), "Ageing well in Wales 2014-19", available at: www.ageingwellinwales.com/Libraries/Documents/ AWFinalEnglish.pdf (accessed 2 March 2019).

Andonian, L. and MacRae, A. (2011), "Well older adults within an urban context: strategies to create and maintain social participation", British fournal of Occupational Therapy, Vol. 74 No. 1, pp. 2-11.

Arts Council for Wales (2018), "Arts and health in wales - a mapping study of current activity. volume 1: analysis, findings and proposals", available at: www.arts.wales/arts-inwales/arts-and-health

Aveyard, H. (2014), "Doing a literature review in health and social care", A Practical Guide, 3rd ed., Open University Press, Maidenhead.

Braun, V. and Clarke, V. (2006), "Using thematic analysis in psychology", Qualitative Research in Psychology, Vol. 3 No. 2, pp. 77-101.

Cantu, A.G. and Fleuriet, K.J. (2017), "Making the ordinary more extraordinary - exploring creativity as a health promotion practice among older adults in a community based professionally taught arts program", fournal of Holistic Nursing, Vol. 36 No. 2, pp. 123-133.

Clift, S. (2012), "Creative arts as a public health resource: moving from practice based research to evidence based research", Perspectives in Public Health, Vol. 132 No. 3, pp. 120-127.

Denscombe, M. (2017), The Good Research Guide for Small Scale Social Research Projects, 6th ed., Open University Press, Maidenhead.

Elo, S., Kaariainen, M., Kanste, O., Polkki, T., Triainen, K. and Kyngas, H. (2014), "Qualitative content analysis: a focus on trustworthiness", SAGE Open, Vol. 4 No. 1, pp. 1-10.

Fraser, K.D., O’Rourke, H.M., Wiens, H., Lai, J., Howell, J. and Brett-MacLean, P. (2015), "A scoping review of research on the arts, aging and quality of life", The Gerontologist, Vol. 55 No. 4, pp. 719-729.

Gallistl, V. (2018), "The emergence of the creative ager - on subject cultures of late life creativity", Fournal of Aging Studies, Vol. 46, pp. 93-99.

Hammell, K.R.W. (2014), "Belonging, occupation, and human well-being: an exploration", Canadian fournal of Occupational Therapy, Vol. 81 No. 1, pp. 39-50.

Holt-Lunstad, J., Smith, T.B., Baker, M., Harris, T. and Stephenson, D. (2015), "Social relationships and mortality risk: a Meta-analytic review", Perspectives on Psychological Science, Vol. 10 No. 2, pp. 227-237.

Kumar, R. (2014), Research Methodology: A Step-by-Step Guide for Beginners, 4th ed., Sage Publications, London.

Law, M., Cooper, B.A., Strong, S., Stewart, D., Rigby, P. and Letts, L. (1996), "The Person-Environment-Occupation model: a transactive approach to occupational performance", Canadian fournal of Occupational Therapy, Vol. 63 No. 1, pp. 9-23.

Leigh-Hunt, N., Bagguley, D., Bash, K., Turner, V., Turnbull, S., Valtorta, N. and Caan, W. (2017), "An overview of systematic reviews on the public health consequences of social isolation and loneliness", Public Health, Vol. 152 No. 171.

McAvinchey, C. (2013), "Coming of age: arts practice with older people in private and domestic spaces", Research in Drama Education: The fournal of Applied Theatre and Performance, Vol. 18 No. 4, pp. 359-373.

O'Shea, E. and Leime, A.N. (2012), "The impact of the bealtaine arts programme on the quality of life, wellbeing and social interaction of older people in Ireland", Ageing \& Society, Vol. 32, pp. 851-872.

Office of National Statistics (2018), "Overview of the UK population: November 2018”, available at: www.ons.gov. $\mathrm{uk} /$ peoplepopulationandcommunity/populationandmigration/ 
populationestimates/articles/overviewoftheukpopulation/ november 2018

Papageorgiou, N., Marquis, R. and Dare, J. (2016), "Identifying the enablers and barriers to community participation amongst older adults", British fournal of Occupational Therapy, Vol. 79 No. 12, pp. 742-751.

Phinney, A., Moody, E.M. and Small, J.A. (2014), "The effect of a community engaged arts program on older Adults wellbeing", Canadian fournal of Aging, Vol. 33 No. 3, pp. 335-345.

Poulos, R.G., Marwood, S., Harkin, D., Opher, S., Clift, S., Cole, A.M.D., Rhee, J., Beilharz, K. and Poulos, C.J. (2019), "Arts on prescription for community-dwelling older people with a range of health and wellness needs", Health $\mathcal{E}$ Social Care in the Community, Vol. 27 No. 2, pp. 483-492.

Riley, J., Corkhill, B. and Morris, C. (2013), "The benefits of knitting for personal and social wellbeing in adulthood: findings from an international survey", British fournal of Occupational Therapy, Vol. 76 No. 2, pp. 50-57.

Roe, B., McCormick, S., Lucas, T., Gallagher, W., Winn, A. and Elkin, S. (2016), "Coffee, cake and culture: evaluation of an art for health programme for older people in the community", Dementia, Vol. 15 No. 4, pp. 539-559.

Royal College of Occupational Therapy (2017), Living, Not Existing: Putting Prevention at the Heart of Care for Older People in Wales, Royal College of Occupational Therapists, London.

Stickley, T., Hui, A., Souter, G. and Mills, D. (2016), "A community arts programme for older people: an evaluation", Mental Health and Social Inclusion, Vol. 20 No. 1, pp. 22-28.

Thew, M., Bell, F. and Flanagan, E. (2017), "Social prescribing: an emerging area for occupational therapy",
British Fournal of Occupational Therapy, Vol. 80 No. 9, pp. 523-524.

Welsh Government (2014), "The strategy for older people in Wales 2013-2023”, available at: http:/gov.wales/topics/ health/publications/socialcare/strategies/older/?lang=en

Wilcock, A.A. (1998), "Reflections on doing, being and becoming", Canadian Fournal of Occupational Therapy, Vol. 65 No. 5, pp. 248-256.

Wilcock, A.A. (2005), "Occupational science: bridging occupation and health", Canadian fournal of Occupational Therapy, Vol. 72 No. 1.

\section{Further reading}

NICE (2015), “Older people: independence and mental wellbeing (NG32)", available at: www.nice.org.uk/guidance/ ng32/

Smallfield, S. and Molitor, W.L. (2018), "Occupational therapy interventions supporting social participation and leisure engagement for community-dwelling older adults: a systematic review", American fournal of Occupational Therapy, Vol. 72 No. 4.

Turcotte, P.-L., Carrier, A., Roy, V. and Levasseur, M. (2018), “Occupational therapists' contributions to fostering older adults' social participation: a scoping review", British Fournal of Occupational Therapy, Vol. 81 No. 8, pp. 427-449.

\section{Corresponding author}

Bethan Owen-booth can be contacted at: b.owen-booth@ glyndwr.ac.uk 